\title{
Have Public Service Reforms Improved the Quality of Service Delivery? Evidences from Selected Executive Agencies in Tanzania
}

\author{
Jerome William Materu ${ }^{1 *}$, William Amos Pallangyo \\ ${ }^{I}$ Occupation and Health Manager at the Occupational Safety and Health Authority (OSHA) Tanzania \\ ${ }^{2}$ Senior Lecturer in Leadership and Management at the Law school of Tanzania
}

*Corresponding Author: Jerome William Materu, Occupation and Health Manager at the Occupational Safety and Health Authority (OSHA) Tanzania

\begin{abstract}
This article assesses the impact of public service reforms on the Quality of Service Delivery (QSD) in two selected executive agencies in Tanzania. The questionnaire were administered to198 clients ofthe two agencies, namely, Registration Insolvency and Trusteeship Agency (RITA) and Business Registrations and Licensing Agency (BRELA).The findings established that majority of the respondents indicated that theQSD was relatively below their expectations. The score for waiting time was $63.1 \%$, promptness was $62.6 \%$, and communication and feedback was $76.4 \%$. The findings further indicated the experiences of corruption and bribery to be $76.3 \%$, stringent and bureaucratic procedures was $51.5 \%$, poor customer care was $71.2 \%$, and nepotism and favoritism was $52.5 \%$. Overall, most respondents, 131 (62.2\%) believed that public service reforms had not improved the QSD in the studied agencies. However, 67 respondents (33.8\%) indicated that public service reforms had improved the delivery of services. The article concludes that public service reform measures may not be successful without eliminating contradicting practices such as bribery, nepotism, and stringent bureaucratic procedures.
\end{abstract}

Keywords: Public service reforms, executive agencies, quality of service delivery, Tanzania

\section{INTRODUCTION}

There have been significant changes in the approaches to delivery of public services over the last three decades. These changes, which are closely connected with the New Public Management (NPM) paradigm in public administration have been at the centre of the Public Sector Reforms, which started in the late 1980s and early 1990s and today continue to provide a framework for improving the performance of public sector organizations (Adamolekun, \& Kiragu, 1999). One of these changes includes taking away of the traditional service delivery responsibilities of the executive government departments and handling them to both private organizations and semi-autonomous agencies (Andrews \& Anwar, 2005).

These two models of service delivery, privatization and agentification are closely related. However, there are some key defining features that present the difference between privatization and agentification (Mutahaba \& Kiragu, 2012; Pollitt, 2006). Although the privatization concept itself is unclear, it might be tentatively defined as a general effort to relieve the disincentives toward efficiency in public organizations by subjecting them to the incentives of the private market (Bailey, 1987).Privatization involves a total shift of service planning, development and delivery activities from the government to market organizations of which the engagement with the service users is moderated by demand, preference, and consuming power. Agentification involves formulation of semiautonomous organizations which borrow and adopt some market principles such as customer focus, innovation, and operational flexibility.

Agentification is defined by considering how it differs from privatization and other related models of service delivery such as outsourcing due to some basic, but important characteristics (Bertrand \& Mullainathan, 2000). The executive agencies retain an identity of being 'public' and perform their duties through contractual arrangements, which are largely informed by the principal-agent framework. Being a case, they have well defined service users, roles, objectives, and some degree of 
financial and operational autonomy (Pollitt, 2006). Under this framework, the government department which is traditionally responsible to deliver certain defined services under its portfolio (let say a ministry) formulates an agency and recruits highly qualified and technically efficient who will be responsible for planning and executing activities that should result in cost effective and efficient delivery of the services.

The focus on the cost-effectiveness and efficiency in the delivery of services makes the day-to-day operations of executive agencies somehow protected from direct political interference. This is because the ultimate goal of agentification is to provide quality services, which should fairly satisfy user expectations (Mutahaba \& Kiragu, 2002; Pollitt, 2006). Being a case, executive agencies are not completely free from control. They principally enjoy operational and process autonomy, but they are answerable and accountable to the public through the political executives, namely the parent ministries that held the service portfolio before establishment of the agencies (Talbot, 2004). Therefore, executive agencies are most responsible for delivery of public services and are solely guided by government policies (Tuwa, 2009; Kiragu \& Mutahaba, 2012). Furthermore, executive agencies stands as a model for reforming public organizations since under the NPM they stood a ground for experimenting how successfully the aforementioned business-world organizational management principles work effectively in the public sector.

The executive agencies have been increasing in public service delivery in both developed and developing countries. However, the answer to whether they have been able to ensure improved quality services, cost effectiveness and efficiency of service delivery to users remains a subject of debate. Despite the existence of evidence that executive agencies have contributed to some recognized improvement in service delivery (McCourt, 2013; Marris, 2018). There are also counter evidences that in some of the countries including Tanzania, executive agencies had resulted in undesired outcomes (Talbot, 2004; Makene, 2008). This is partly attributed to inefficient management of the reforms, poor coordination, limited autonomy and continuous political interference (Mlinga, 2014; Pallangyo \& Rees, 2010). The undesired outcomes were also associated with corruption and selfaggrandizement and limited accountability. The large percentage of executive agencies resources were directed to organizational management aspects, which hardly contribute to QSD improvement. The executive agencies resources were directed to such as irrational capacity building interventions and paying higher salaries to underperforming staff (Pollitt, 2007; Cameron, 2009).

Tuwa (2009) associated agentification with increased operational autonomy. This is justified by a study by Caulfield (2002) found that the Tanzania Civil Aviation Authority, one of the executive agencies had affected efficiency in the management of international debt leading into a grand corruption that involved the purchase of low quality equipment on debt worth $£ 28$ million from Aerospace, a British private company. Tuwa (2009) also observed that responsiveness to service users was still a problem among executive agencies. Sulle (2010) found that agentification was affected by the coexistence of the NPM principles and the features of the NPM, which were contradicting when it comes to improving the delivery of public goods and services by executive agencies (URT, 2005). Overall, there is no single strait answer regarding the effect of agentification reforms on the QSD. Previous research presented mixed findings that suggested the need to take stock of the effects as particularistic and not universal.

Against this overview, this paper presents quantitative results from a broad mixed method study which aimed at assessing the impact of public service reforms on the quality of service delivery using two selected executive agencies in Tanzania. The analysis is informed by a user-centered perspective through which the quality of service delivery is defined in terms of how the users perceive the service provided by an organization as well as the ways through which the services are delivered to the users. Under this perspective, it is assumed that the users have rich experience of how the services were offered before and after the changes associated with the reforms (Cosby \& Phillip, 1979). In connection with the reforms and their implementation, the users will develop some expectations which guide their assessment of whether the services meet the expected quality or not (Lewis \& Mitchell, 1990). The QSD is therefore defined in terms of whether the services are provided in the way that they meet the users' needs and interests (Karyeija, 2012; Zeithaml, Berry \& Parasuraman, 1996). The details of QSD indicators are presented in the methods section. 


\section{MeTHODOLOGY}

This paper is based on case studies of two selected executive agencies, namely the Registration Insolvency and Trusteeship Agency (RITA) and Business Registrations and Licensing Agency (BRELA). The cross-sectional survey was used to depict a distribution of characteristics of interests in the study population, in this case the service users or clients. A descriptive analysis of the comparable information on the quality of service delivery was based on the users' expectations (Bulmer, 2017). The questionnaire allowed the study to compare the perceptions of respondents (Bell et al., 2007) regarding the quality of services experienced at the point of service delivery.

The study assumed that random sampling would reduce bias and ensure that all available clients of the agencies had a fairly equal opportunity for inclusion (Saunders, 2012). Simple random sampling was used to select the respondents. The register list of clients who were waiting for the services during the three data collection days for each of the three organizations formed the sampling frame $(\mathrm{N}=459)$.

A three-digit table of random numbers was used to select respondents depending on the number of respondents who were waiting for the services at the agencies' offices. Each number in the table that matched with the number in the register was selected randomly. The random selection ensured that all clients had come had equal chance of being selected and included in the sample. The sample included register clients waiting for the service and ability to speak Kiswahili or English languages. The sample excluded were those who were not willing to participate in the study. All the questionnaires were administered at the agencies' offices and each questionnaire set took between 15 and 20 minutes.

The questionnaires were checked for errors before starting the coding process. Data coding was done using a Statistical Package for Social Sciences (SPSS). The questionnaires were processed by generating frequency tables and conducting descriptive analyses to examine if there were data entry and coding errors. The Cronbach reliability test was conducted for the consistency and the alpha value for all items was 0.595. When each of the two item categories was tested separately, the alpha improved to 0.929 indicating very high consistency.

The data were processed to generate frequency and percent tables, which were manually examined to discover the patterns shown by proportional statistics. In addition to proportional statistics, the chisquare test of independence was used to examine the influence of social demographic differences on

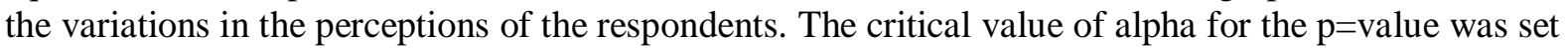
at 0.05 meaning that the p-value of less than 0.05 showed statistical significance. The Cramer's measures of effect size were used to compare the influence for each of the social demographic variables. The effect size based on Cramer's rule was determined using the thresholds of $0.0>0.10$ (weak), $0.10>0.30$ (moderate), and $>0.30$ (strong) $(\mathrm{CI}=95 \%, \mathrm{df}=4)$.

This study entailed ethical considerations by following a proper procedure in ensuring academic and scientific integrity (Kothari 2004). This included checking the scientific and methodological credibility and selection of appropriate research methods. The respondents were free to agree or refuse to participate in the study, to decline from answering any question. In addition, there was a protection of respondents' privacy

\section{RESUlTS}

The results section is organized under three main subsections. The first presents the key social demographic characteristics of the respondents. The second provides a descriptive analysis of the respondents' perceptions on improvement in the QSD and existence of maladministration practices that affect QSD. The third and last considers the extent to which each of the selected social demographic characteristics is associated with variations in the QSD perceptions. The next subsection embarks on the respondents social demographic characteristics.

\subsection{Respondents' Social Demographic Characteristics}

The planned respondents were 200 whose 198 (99\%) including 111 (56.1\%) males and 87 (48.9\%) females participated in the study. There were equal proportions of participants from the two organizations namely RITA and BRELA. Table 1 summarizes the distribution of respondents in the sample by different social demographic variables. It was the first time for the majority of the respondents $(78.7 \%)$ to seek the service from the organizations, $20 \%$ had sought the service two to 
Have Public Service Reforms Improved the Quality of Service Delivery? Evidences from Selected Executive Agencies in Tanzania

three times, and few had more than three times experience of receiving services from RITA and BRELA. The most common services sought were birth and death certificates for RITA and company registration and trademark registration for BRELA. Majority of the respondents were Tanzanians (97.6\%) in either young (40.4) or young adults $(48.5 \%)$ age.

Table1: Respondents' social demographic characteristics for selected variables

\begin{tabular}{|l|l|l|}
\hline \multicolumn{1}{|c|}{ Cariable: } & \multicolumn{1}{c|}{$\mathbf{n}$} & \multicolumn{1}{c|}{$(\%)$} \\
\hline \multicolumn{1}{|c|}{ Male } & & \\
\hline Respondent sex: & 111 & $(56.1)$ \\
\hline Female & 87 & $(43.9)$ \\
\hline Organization: Nones & 99 & $(50.0)$ \\
\hline Rita & 99 & $(50.0)$ \\
\hline Service seeking frequency: & 146 & $(73.7)$ \\
\hline 2 to 3 times & 40 & $(20.2)$ \\
\hline 4 to 5 times & 10 & $(5.1)$ \\
\hline More than 5 times & 2 & $(1.0)$ \\
\hline Service sought from RITA: & 129 & $(65.2)$ \\
\hline Birth certificate & 28 & $(14.1)$ \\
\hline Death certificate & 4 & $(2.0)$ \\
\hline Company liquidation & 5 & $(2.5)$ \\
\hline Will & 1 & $(.5)$ \\
\hline Public trustee & 31 & $(15.7)$ \\
\hline Service sought from BRELA: & 101 & $(51.0)$ \\
\hline Company registration & 57 & $(28.8)$ \\
\hline Trade/service mark & 19 & $(9.6)$ \\
\hline Patent license & 10 & $(5.1)$ \\
\hline Industrial license & 7 & $(3.5)$ \\
\hline Business licence & 4 & $(2 . .0)$ \\
\hline Respondent age: $<18$ & 2 & $(1.0)$ \\
\hline 18 to 35 years & 2 & $(40.4)$ \\
\hline 36 to 52 years & 80 & $(48.5)$ \\
\hline 53 to 69 years & 96 & $(10.1)$ \\
\hline Education: <primary education & 20 & $(1.5)$ \\
\hline Primary education & 3 & $(16.2)$ \\
\hline Secondary education & 32 & $(51.5)$ \\
\hline Higher education (non-university degree) & 102 & $(16.7)$ \\
\hline Higher education (university degree) & 33 & $(14.1)$ \\
\hline Nationality: Tanzanian & 28 & $(97.5)$ \\
\hline Other nationalities & 193 & $(2.5)$ \\
\hline Occupation/employer: Public sector & 5 & $(12.6)$ \\
\hline Formal non-public sectors & 25 & $(5.1)$ \\
\hline Informal non-public sector & 10 & $(1.6)$ \\
\hline Self-employed & 23 & $(58.6)$ \\
\hline Not currently employed & 116 & $(12.1)$ \\
\hline
\end{tabular}

In terms of the respondents' occupation, the majority of the respondents $(58.6 \%)$ were self-employed individuals and the rest included public sector employees, unemployed, and informal non-public sector employees who had equal proportions, especially $25 \%, 24 \%$, and $23 \%$ respectively. Only $5.1 \%$ of the participants were employed in the form private sector organizations. The variations in social demographic characteristics were important since they were thought to affect both the awareness and perceptions of QSD improvement as associated with public service reforms and related measures in the organizations.

\subsection{Perceptions about the Quality of Service Delivery}

Two categories of QSD indicators were assessed. First, the improvement in efficiency such as waiting time, innovation, promptness, reliability, professionalisms, and creativity, and second, the existence/absence of maladministration indicators that affect the QSD such as corruption, nepotism, poor technology, and unnecessarily stringent procedures that affects. Whereas the former focuses 
Have Public Service Reforms Improved the Quality of Service Delivery? Evidences from Selected Executive Agencies in Tanzania

largely on the customer's evaluation of services they receive, the later relates to defects in the agencies that public service reform measures sought to eliminate.

\subsection{Overall Perceptions of the Impact of Reforms on the QSD}

As an entry point, the respondents were asked whether they considered public service reforms to have contributed to improvement in the QSD in the study organizations. Many of the respondents 131 (62.2\%) believed reforms had not improved service delivery in the agencies. On the other hand, 67 $(33.8 \%)$ believed the reforms had improved the delivery of services. From this point, it was important to consider the perceptions of the respondents on each of the selected QSD improvement indicators, which are presented in the next subsection.

\subsection{Improvement in the Key QSD Indicators}

Twelve indicators, which were selected for ranking the perceived QSD was were rated by the respondents with the first six using the five scale from 'very poor' to 'very good' and the other six from 'very low' to 'very high'. The statistical results for all the 12 indicators are comparatively presented in Table 2.

Table2: Scores on Selected QSD improvement indicators

\begin{tabular}{|l|l|l|l|l|l|}
\hline \multicolumn{1}{|c|}{ QSD improvement indicator } & \multicolumn{1}{|c|}{ Very poor } & \multicolumn{1}{|c|}{ Poor } & Satisfactory & \multicolumn{1}{|c|}{ Good } & $\begin{array}{l}\text { Very } \\
\text { good }\end{array}$ \\
\hline Waiting time before getting service & $4(2)$ & $125(63.1)$ & - & $69(34.8)$ & - \\
\hline Staff creativity and innovation & - & $47(23.7)$ & $2(1.0)$ & $149(24.7)$ & - \\
\hline Promptness of staff during enquiries & - & $124(62.6)$ & - & $74(37.4)$ & - \\
\hline Efficiency and professionalism & & $61(30.8)$ & $1(0.5)$ & $136(68.7 \%)$ & - \\
\hline Reliability and dependability & & $53(26.8)$ & $4(2)$ & $141(71.2 \%)$ & - \\
\hline Transparency and accountability & - & $74(37.4)$ & $1(0.5)$ & $123(62.1)$ & - \\
\hline $\begin{array}{l}\text { QSD improvement indicator } \\
\text { Flexibly encouraging creativity and low } \\
\text { innovation }\end{array}$ & Very & $\begin{array}{l}\text { Neither low } \\
\text { nor high }\end{array}$ & $\begin{array}{l}\text { Very } \\
\text { high }\end{array}$ \\
\hline $\begin{array}{l}\text { Emotional intelligence, listening, handling } \\
\text { rifts }\end{array}$ & $7(3.5)$ & $53(31.8)$ & $2(1.0)$ & $133(67.2)$ & $1(0.5)$ \\
\hline Employees' motivation to serve clients & $9(4.5)$ & $71(35.9)$ & $5(2.5)$ & $113(57.1)$ & - \\
\hline $\begin{array}{l}\text { Delegating, sharing, and higher } \\
\text { participation }\end{array}$ & $7(3.5)$ & $65(32.8)$ & - & $126(63.6)$ & - \\
\hline Effective communication and feedback & $47(23.7)$ & $77(38.9)$ & - & $7(2.0)$ & - \\
\hline Employees demonstrate technical maturity & $7(3.5)$ & $80(40.4)$ & $1(0.5)$ & $110(55.6)$ & - \\
\hline
\end{tabular}

The results in table 2 show that the clients had mixed perceptions regarding improvement in the quality of service delivery. There were perceptions that QSD was good in terms of efficiency and professionalism in the delivery of services (68.7\%), reliability and dependability $(71.2 \%)$ and transparency and accountability (62.1\%). Similarly, respondents thought there was relatively high improvement in terms of flexibility and encouraging innovation $(68.7 \%)$, emotional intelligence (63.6\%), sharing and participation (63.6\%), motivation to serve (57.1\%), and technical maturity of the employees who were providing the services.

Despite these improvements, the respondents thought the QSD was poor in terms of waiting time $(63.1 \%)$, promptness $(62.6 \%)$, and communication and feedback $(76.4 \%)$. The improvement was also perceived to be low in terms of communication and feedback (61.6\%). Overall, the improvements are more revealed in terms of operational efficiency, but less in terms of dealing with the users and satisfying their needs and expectations.

\subsection{Experiences of Maladministration}

When one attempts to assess the improvement in the QSD, it is also important to think about the possibility of having in place some forces that constrain the improvement despite the efforts to implement reform measures for delivering quality services. In this respect, eight indicators of existence of maladministration practices affecting the improvement in the perceived QSD were assessed. These were the existence of cumbersome bureaucratic procedures, poor or negative 
Have Public Service Reforms Improved the Quality of Service Delivery? Evidences from Selected Executive Agencies in Tanzania

communication, poor customer care, corruption and bribery, nepotism and favoritism, use of unskilled or incompetent personnel, use of poor equipment and technology, and social stigmatization in the delivery of services. This was done by asking each respondent to rate whether they had experienced the existence of those practices in the agencies along a five-point scale ranging from 'never' to 'very often'. The results for each of the eight indicators are presented in Table 3.

Table3: Perceptions on the existence of maladministration affecting QSD improvement

\begin{tabular}{|l|l|l|l|l|l|}
\hline Experienced maladministration indicators & \multicolumn{1}{|c|}{ Never } & Very rare & \multicolumn{1}{c|}{ Rare } & \multicolumn{1}{c|}{ Often } & \multicolumn{1}{|l|}{ Very often } \\
\hline Cumbersome and bureaucratic procedures & $39(19.7)$ & $8(4.0)$ & $49(24.7)$ & $93(47.0)$ & $9(4.5)$ \\
\hline Poor/negative communication with clients & $37(18.7)$ & $8(4.0)$ & $46(23.2)$ & $104(52.5)$ & $3(1.5)$ \\
\hline Poor customer care/not customer concerned & $34(17.2)$ & $8(4.0)$ & $15(7.6)$ & $138(69.7)$ & $3(1.5)$ \\
\hline Corruption and bribery & $30(15.2)$ & $5(2.5)$ & $12(6.1)$ & $135(68.2)$ & $16(8.1)$ \\
\hline Nepotism and favouritism & $31(15.7)$ & $1(0.5)$ & $62(31.3)$ & $97(49.0)$ & $7(3.5)$ \\
\hline Use of unskilled/incompetent personnel & $32(16.2)$ & $6(3.0)$ & $83(41.9)$ & $75(37.9)$ & $2(1.0)$ \\
\hline Use of poor equipment and technology & $32(16.2)$ & $2(1.0)$ & $78(39.4)$ & $85(42.9)$ & $1(.5)$ \\
\hline Social stigmatization & $41(20.7)$ & $3(1.5)$ & $37(18.7)$ & $103(52.0)$ & $14(7.1)$ \\
\hline
\end{tabular}

As revealed by statistical results in Table 3, there was noticeable proportions of respondents who had never (range $=20.7 \%-15.2 \%$ ) experienced the maladministration practices or experienced them very rarely (range $=0.5 \%-4.0 \%$ ). The proportions were larger for those who rarely experienced the maladministration practices, ranging from $6.1 \%$ for corruption and bribery to $41.9 \%$ for use of unskilled and incompetent personnel.

On the other hand, the proportions of those who experienced the maladministration practices often or very often were more significant for all the eight indicators (range $=38.8 \%-76.3 \%$ ). However, experiences of corruption and bribery $(76.3 \%)$, stringent and bureaucratic procedures $(51.5 \%)$, and poor customer care $(71.2 \%)$, and nepotism and favouritism $(52.5 \%)$; which affected quality of service delivery were commonly reported. Overall, corruption and bribery was reported to be the most common experience $(76.3 \%)$ followed by poor customer care or limited concern for customers $(71.2 \%)$, negative communication $(54.0 \%)$, nepotism and favouritism $(52.7 \%)$, and cumbersome bureaucratic procedures. The existences of these experiences undermine successful use of the reform measures by the agencies to improve the QSD as expected and experienced by the service users. In the next subsection we proceed to consider the extent to which social demographic differences have influence on the variation in the perceptions about the QSD in the agencies.

\subsection{Influence of Social Demographic Variations on QSD Perceptions}

Social demographic variables are important because they shape the perceptions of individuals about the phenomena around them. We therefore wanted to find out the extent to which the difference in perceptions about the QSD and related improvement and practices affecting improvement were influenced by social demographic differences among respondents. Seven social demographic variables namely age, sex, education, nationality, services sought, and agency from which the service was sought were tested using chi-square statistics. Statistical results are presented in table 4.

Table4: Influence of demographics on quality improvement perceptions $(C I=95 \%, \alpha=0.005)$

\begin{tabular}{|l|l|l|l|l|}
\hline Variable & $\mathbf{X}^{\mathbf{2}}$ & $\mathbf{d f}$ & $\mathbf{p}$-value & Cramer's V \\
\hline Respondent age & 201.783 & 8 & 0.000 & 0.712 \\
\hline Respondent sex & 200.914 & 4 & 0.000 & 0.710 \\
\hline Respondent education level & 209.824 & 4 & 0.002 & 0.719 \\
\hline Respondent nationality & 199.441 & 4 & 0.011 & 0.708 \\
\hline Type of the services sought & 206.590 & 14 & 0.116 & 0.720 \\
\hline Agency from which the service was sought & 199.567 & 10 & 0.010 & 0.708 \\
\hline Respondents' service seeking frequency & 202.472 & 8 & 0.000 & 0.713 \\
\hline $\begin{array}{l}\text { X2= Pearson's Chi-Square, df=degree of freedom, p=probability of occurring by chance, I=confidence } \\
\text { interval, } \alpha=\text { alpha }\end{array}$
\end{tabular}

The results of the chi-square test in table 4.30 show that all the social demographic variables (except the service sought by respondents, $\mathrm{p}=0.116$ ) had statistically significantly relationship with the variations in the perceptions $(\mathrm{p}<0.05)$. Variations in age, sex, education, nationality, and the agency 
from which the service was sought, and service seeking frequency were significantly responsible for variations in the perceptions about the quality of service delivered by the agencies.

In terms of the effect size, respondent education level had the highest influence $\left(X^{2}=209.824\right.$, Cramer's V $=0.719)$, followed by the respondents' service seeking frequency $\left(X^{2}=202.472\right.$, Cramer's $V=0.713)$, then respondent age $\left(X^{2}=201.783\right.$, Cramer's $\left.V=0.712\right)$, respondent sex $\left(X^{2}=200.914\right.$, Cramer's V $=0.710)$, agency $\left(\mathrm{X}^{2}=199.567\right.$, Cramer's $\left.\mathrm{V}=0.708\right)$, and finally the respondent nationality $\left(X^{2}=199.441\right.$, Cramer's V=0.708). Overall, variations in all these variables had strong influence on the variations in the perceptions regarding the quality of services. Having considered the influence of social demographic differences, the next section provides a discussion of the findings.

\section{DISCUSSION}

The aim of this study was to assess the impact of public service reforms on the QSD in selected executive agencies from the user viewpoint. The study results revealed variations in both the perceptions of QSD improvement and the influence of the reforms on QSD improvement. From the respondents' point of view, it was insisted from the findings that improvement in the QSD remains limited.

As found early by Pollitt (2007), the findings confirm that the implementation of the reform measures in executive agencies to a large extent falls short of the expectations. It can be learnt from the findings that much of the improvement have been in terms of strengthening operational and process efficiency within the agencies. This is reflected by the fact that many of the respondents thought there were improvement in areas related to professionalism, predictability, reliability, and dependability. On the other hand, communication and focusing on customer needs and preference appear to remain a challenge among executive agencies. These findings are supported by the previous findings by Tuwa (2009) whose study found that the improvement were in terms of autonomy and flexibility, but will limited improvement in terms of being accountable and responsive to the public.

As it was for many of the previous studies (Pollitt, 2007; Walker \& Boyne, 2006), the findings demonstrated that the improvement in the QSD were not consistently improved in all the key QSD improvement indicators. It is not clear, however, whether the varying improvement across the QSD indicators has been an intended effect of prioritization of the areas for improvement or it has been accidental. An alternative observation could be that the improvement in aspects such as reliability, dependability, professionalism, and predictability are connected with an inevitably increasing investment in service delivery technologies including Information Communication Technologies (ICTs), which have been a priority of both RITA and BRELA (Materu, 2018). This has an implication on QSD since the focus on improving internal efficiency with little focus on satisfying user's needs is less likely to improve the quality as interpreted from the users' point of view. Instead, it is more likely to improve the quality from the agencies' point of view which focuses on technical and operational efficiency.

The coexistence of maladministration practices with the best practices unidentified under the reforms and the NPM paradigm has been identified as a common barrier that limits the implementation of public service reforms in less institutionalized public sector organizations (Mutahaba \& Kiragu; McCourt, 2013). As our findings have revealed, there is a sharp divergence between what is documented as guiding principles for improving service delivery within the agencies and the actual experiences on the ground. The study findings insist the need to recognize and appreciate the role of unforeseen and unintended effects of agentification such as rent seeking, misuse of autonomy conferred to the executives of executive agencies, corruption, and attrition of qualified manpower from traditional government departments making them less capable of performing their mandates (Cameron, 2009; Caulfield, 2002). Due to these unintended effects, many executive agencies in the third world countries have found themselves falling short of realizing the hypothesized effects of agentification (Cameron, 2009; Pollitt, 2007). The findings further shows the need to consider the influence of contextual factors that are identified by Ngowi (2008) and Sulle (2009) as traditional and long rooted ideological traits of the Tanzanian public service such as hierarchical control, limited innovation, and bureaucratic procedures that limit flexibility and innovation.

The analysis of the influence of social demographic characteristics of the respondents on the perceptions relating to the QSD has revealed a significant influence of social demographic variations 
on the variations regarding QSD improvement. These findings present a message that efforts to satisfy the needs, interests, and expectations may not necessarily be received in the same by all users. This is because social demographic differences shape the needs, interests, and expectations, as well as the response of the people towards services in different ways (Ganesan-Lim, Russell-Bennett \& Dagger, 2008). In agreement with the current study, previous studies have identified age, sex, education, income, and occupation as strongly influencing how people define their connection with service providers as well as the quality and acceptability of services including health care services (Damian, 2018; Christia \& Ard, 2016). The differences in the identified social demographic characteristics need to be highly considered when attempting to investigate the impact of public service reforms on the quality of service delivery in executive agencies. Therefore, considering the clients' perceptions alone may not provide a clear picture of the relationship between the reforms and QSD perceptions.

Our findings present an important message that need to be considered by both public service management practitioners and researchers. First, the efforts and initiatives to improve the quality of services as part of public service reforms need to be both internal and external focused. To be precise, the focus on operational and processes efficiency may not necessarily imply improvement in the eyes of service users. The users have legitimate expectations on how the service should be delivered, which may not converge with those of the service providers. Therefore, considering their needs, wants, interests, and making them feel that the services are responsive to their needs is important. Second, QSD is a multidimensional phenomenon, which has many indicators some of which may not apply universally. The improvement in one indicators may not necessarily mean improvement in all the indicators. It is therefore important for executive agencies and other service delivery organizations to identify priority aspects in which improvement would have positive effect on the technical side of the organization but also on satisfying the needs and preferences of the users. Third and last, the limitation of statistical analysis of the perceptions regarding QSD indicators and how they are associated with reform measures in executive agencies has been acknowledged. It is therefore worth learning that future studies on the impact of public service reforms on the QSD and related phenomena should go beyond the perceptions to understand how those perceptions are shaped by organizational contexts as well as the wider social, economic, and political environments in which the organizations deliver services as well as the institutional contexts surrounding the implementation of reforms.

\section{CONCLUSION}

The study concludes that there has been some improvement in terms of service outreach expansion and predictability of the services due to the application of the key reform principles such as flexibility and innovation. However, the observed retention of the old bureaucratic procedural characteristics in the delivery of services and the surviving old maladministration practices and perceptions such as nepotism, favoritism, and corruption undermine the potential contribution of the reforms to improved QSD in executive agencies. This pattern represents a contradiction between the NPM values that guide public service reforms such as flexibility, efficiency, professionalism, customer focus, and innovation with traditional values of public administration such as compliance, strict bureaucratic rules, and top-down hierarchical control. Chances for increased contribution of the reforms to improved QSD may not significantly improve without rational interventions to transform executive agencies so that they effectively implement the NPM principles in their day-to-day delivery of services.

\section{REFERENCE}

[1] Adamolekun, L \& Kiragu, K. (1999). Public Administration Reforms. In Adamolekun, L. ed. (1999), Public Administration in Africa: Main Issues and Selected Country Studies. West view: Boulder.

[2] Andrews, M \& Anwar, S. (2005). Citizen-Centered Governance: A new approach to public service reform" In: Anwar, S (Ed), Public Expenditure Analysis, 152 - 82 Washington DC: World Bank.

[3] BAILEY, R. W. (1987), "Uses and Misuses of Privatization", in Steve H.

[4] Hanke (Ed.) Prospects for Privatization, New York, the Academy of Political Science

[5] Bell, A. (2007). Designing and testing questionnaires for children. Journal of Research in Nursing, 12(5), 461-469.

[6] Bertrand, M. \& Mullainathan, S. (2000). Agents with and without Principals. The American Economic Review; 90(2): 203-208. 
Have Public Service Reforms Improved the Quality of Service Delivery? Evidences from Selected Executive Agencies in Tanzania

[7] Bulmer, M. (2017). Sociological Research Methods. Abingdon-on-Thames: Routledge

[8] Caulfield, J. (2002). Executive Agencies in Tanzania: Liberalization and Third World Debt. Public Administration and Development, 22(3), 209-220.

[9] Christia, J \& ARD, A. (2016). The influence of demographic characteristics on service quality perceptions. Journal of Marketing Management, 4(2), 57-62

[10] Crosby, C. \& Philip, B. (1979). Quality is Free: The Art of Making Quality Certain, New York: New American library.

[11] Damian, R.S. (2018). Community Empowerment and Accountability in Rural Primary Health Care: The Case of Kasulu District in Tanzania. PhD Thesis (Unpublished), University of Dar es Salaam.

[12] Ganesan-Lim, C., Russell-Bennett, R., \& Dagger, T. (2008). The impact of service contact type and demographic characteristics on service quality perceptions. Journal of services Marketing, 22(7), 550-561.

[13] Karyeija, G. (2012). Public Service Review, Unpublished PhD Dissertation, University of Bergen. Retrieved from: http://dx.doi.org/10.5539/ass.v8n4p159 on 13 March 2017.

[14] Kiragu, K. \& Mutahaba, G. (2012). Public Service Reform in Eastern and Southern Africa: Issues and Challenges. Dar-es-Salaam: Mkuki na Nyota.

[15] Lewis, B. R., \& Mitchell, V. W. (1990). Defining and Measuring the Quality of Customer Service. Marketing Intelligence \& Planning, 8(6), 11-17.

[16] Makene, D (2008), Challenges Facing the Executive Agencies on Service Delivery in Tanzania. Unpublished MBA Dissertation, Open University of Tanzania

[17] Marris, P. (2018). Dilemmas of social reform: poverty and community action in the United States. New York: Routledge.

[18] Materu, J.W. (2018). The Impact of Public Service Reform on Quality of Service Delivery: The Case of Two Selected Executive Government Agencies in Tanzania. PhD (Unpublished). Open University of Tanzania

[19] McCourt, W. (2013). Models of Public Service Reform: A Problem-Solving Approach. The World Bank Policy Research Working Paper No. 2468. Washington DC: World Bank.

[20] Mutahaba, G. \& Kiragu, K. (2002). Lessons of International and African Perspectives on Public Service Reform: Examples from Five African Countries. African Development, XXVII, (3\&4), 48-75

[21] Saunders, M.; Lewis, P \& Thornhill, A. (2012). Research Methods for Business Students, Edinburg: Pitman Publishing.

[22] Talbot, C. (2004). Executive Agencies: Have they Improved Management in Government. Public Money and Management, 24(2), 104-112.

[23] Tuwa, H. (2009), Assessing Performance Accountability by executive Agencies to the Public in Tanzania. MA Dissertation (Unpublished). University of Dar es Salaam.

[24] URT, (2005). Executive Agencies: Do They Perform Better? (Part I: Main Report) Monitoring and Evaluation Unit. Dar es Salaam: Public Service Reform Programme, President's Office -Public Service Management.

[25] Zeithaml, V. A.; Berry, L. L., \& Parasuraman, A. (1996). The Behavioral Consequences of Service Quality. The Journal of Marketing, 31-46

Citation: Jerome William Materu, William Amos Pallangyo. "Have Public Service Reforms Improved the Quality of Service Delivery? Evidences from Selected Executive Agencies in Tanzania” International Journal of Political Science (IJPS), vol 5, no.4, 2019, pp. 15-23. doi: http://dx.doi.org/10.20431/2454-9452.0504003.

Copyright: (c) 2019 Authors. This is an open-access article distributed under the terms of the Creative Commons Attribution License, which permits unrestricted use, distribution, and reproduction in any medium, provided the original author and source are credited. 